\title{
Scopolamine effects on a one-trial test of fear conditioning'
}

HUGH L. EVANS AND R. A. PATTON, DEPARTMENT OF PSYCHOLOGY, UNIVERSITY OF PITTSBURGH, Pittsburgh, Pa. 15213

Conditioned suppression was demonstrated in rats trained under nondrug conditions and tested under either drug or nondrug conditions. When training occurred under drug conditions, suppression occurred only when testing was also under the drug. Results are interpreted in terms of dissociation between drug and nondrug states rather than as effects on mechanisms of learning and memory.

Several theorists have proposed that neurophysiological mechanisms underlying learning and memory may involve acetylcholine as a crucial transmitter substance in the brain (Carlton, 1963; Deutsch \& Deutsch, 1966). Recently, anticholinergic substances have been used to investigate the acquisition and retention of a variety of behaviors. The muscarinic blocking agents, scopolamine and atropine, reliably produce a deficit in passive avoidance learning (Buresova et al, 1964; Bohdanecky \& Jarvik, 1967; Dilts \& Berry, 1967), but have been reported to have no significant influence on acquisition of "conditioned fear" or conditioned suppression (Vogel et al, 1967).

Internal effects induced by anticholinergic agents can function as discriminative stimuli (Barry \& Kubena, 1967) and a change in drug state may affect performance through a type of generalization decrement or dissociation (Overton, 1966; Oliverio, 1968). Few studies have evaluated behavior with both training and testing under drug conditions, a potentially important control for dissociative effects. The present study, a variation of the conditioned suppression design of Leaf \& Leaf (1966), was planned to evaluate the interaction of scopolamine and fear on a consummatory response, drinking.

Method. Subjects (Ss), 72 naive male Sprague-Dawley Holtzman rats weighing $277-340 \mathrm{~g}$ when the experiment began, were maintained in individual cages with food and water ad lib except on test days. Ss were randomly assigned to one of eight groups and were tested at the midst of the dark phase of their daily light/dark cycle.

Six boxes, $14 \times 7 \times 6.5$ in. high, were equipped with detachable Grason-Stadler drinkometers and water bottles. Foot shock was presented through the wire floors of the boxes by Lehigh Valley 1531 constant current generators. Tones were presented by a Foringer 1166 tone generator through a 6 in. speaker located $4 \mathrm{ft}$ from the test boxes. Apparatus was controlled by programming equipment located in an adjacent room.

On Day 1 water was removed from the Ss' home cages. On Day 2 each 24-h deprived $S$ was given $5 \mathrm{~min}$ access to water in one of the test boxes. Time, in tenths of seconds, to completion of the first 100 licks at the drinking tube was recorded, as well as the total number of licking responses during the session. After this session Ss were returned to ad lib water in their home cages. On Day 3 the drinking tube was not available in the test boxes and trials were administered according to a 2 by 2 by 2 factorial design. The variables were: Day 3 shock or no-shock, Day 3 drug treatment, and drug treatment on the Day 5 test. Each of the eight groups received a drug treatment consiting of either $1 \mathrm{mg} / \mathrm{cc} / \mathrm{kg}$ of scopolamine $\mathrm{HBr}$ in physiological saline or $1 \mathrm{cc} / \mathrm{kg}$ of saline, injected i.p. $30 \mathrm{~min}$ prior to the start of the conditioning session. Ss in the shock groups were given 4 tone-shock presentations, each presentation involving a tone of $15 \mathrm{sec}$ duration terminating with $2.0 \mathrm{sec}$ of $0.8 \mathrm{~mA}$ shock. The interpresentation interval was $60 \mathrm{sec}$. Ss in the no-shock groups were presented the tone without shock. Days 2 and 3 constituted the training procedure.

On Day 4 water was removed from the home cages. On Day 5 the 24-h deprived Ss were injected $30 \mathrm{~min}$ prior to a $5 \mathrm{~min}$ test session in the box with the drinking tube present. Time to completion of the first 100 licks was recorded. Four tone presentations were given in the same manner as on Day 3 but without shock. The Day 5 test was used as a measure of conditioned fear.

Results and Discussion. Latencies to the completion of 100 responses were normalized by reciprocal transformation and subjected to analysis of covariance. Pretest (Day 2) latencies were the adjusting variable. The overall effect of shock was significant

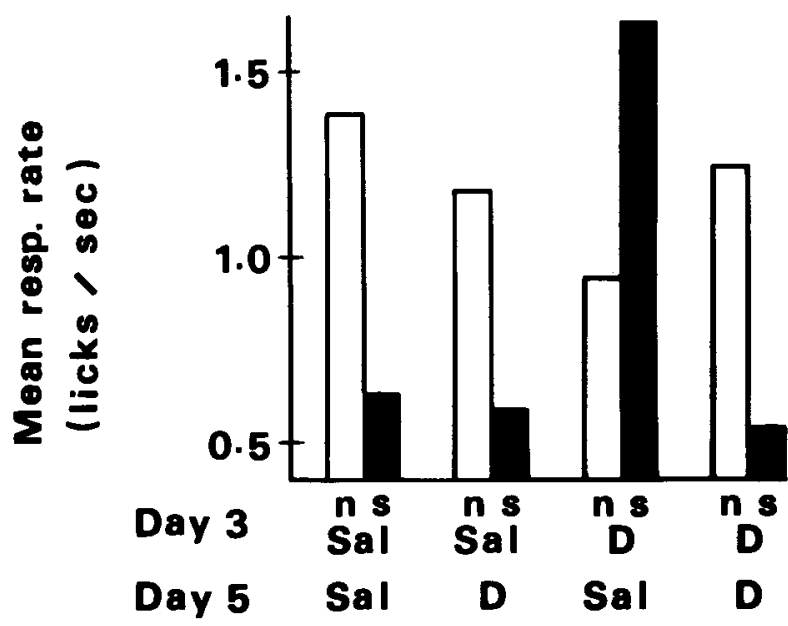

Fig. 1. Mean response rates on Day 5 test, "Sal" = saline, "D" = drug. Day 3 treatment: " $n$ " = no-shock, "s" = shock.

$(F=8.571, \mathrm{df}=1 / 63, \mathrm{p}<.05)$. The second order interaction (Day 3 injection by Day 5 injection by shock condition) was significant $(\mathrm{F}=4.385, \mathrm{df}=1 / 63, \mathrm{p}<.05)$. Response rates for the duration of the first 100 responses on the Day 5 test of the eight groups are shown in Fig. 1. The percentage of total Day 5 responses occurring during tone presentation was calculated as an index of conditioned suppression. Analysis of variance revealed no significant effects on this measure. Perhaps there were an insufficient number of tone-shock pairings, or the method of tone presentation was inadequate to establish the tone as a discriminative cue.

The two groups of saline-injected Ss exposed to fear conditioning showed a suppression of drinking on Day 5 in comparison with the two no-shock control groups (Fig. 1). This may be attributed to the disruptive effects of fear elicited by stimuli in the test apparatus. The suppression was consistent whether Day 5 testing was under drug or nondrug conditions. However, Ss shocked under scopolamine showed subsequent suppression of drinking only if tested under scopolamine. Ss shocked under the drug and tested under saline did not show the effects of conditioned suppression when compared to no-shock controls, i.e., there was a failure of transfer of training from the drug to the nondrug state ${ }^{2}$. Ss having both Day 2 drinking and Day 3 shock in the nondrug state showed suppression in the drug state. None of the above results suggest that scopolamine affects mechanisms of learning or memory, although it is evident that the drug can block expression of conditioned fear under some circumstances.

The present experiment differed from those of Vogel et al (1967) in that treatment consisted of $1.0 \mathrm{mg} / \mathrm{kg}$ scopolamine given $30 \mathrm{~min}$ before testing instead of $0.6 \mathrm{mg} / \mathrm{kg}$ given $20 \mathrm{~min}$ before. The $1.0 \mathrm{mg} / \mathrm{kg}$ dose did not, by itself, significantly affect water consumption or drinking rate. Clear evidence of dissociation with anticholinergics has been reported only under very high doses (Overton, 1966). The present experiment indicates that $1.0 \mathrm{mg} / \mathrm{kg}$ of scopolamine is sufficient to produce a decrement in performance when the shift is from drug to the nondrug state. This decrement is not interpreted as an effect on learning or memory per se, but rather the result of altered stimulus conditions in the experimental environment caused by change of drug state. Investigators have failed to influence learning or memory when scopolamine is given immediately after training but considerably prior to testing (Bohdanecky \& Jarvik, 1967), an observation consistent with the present interpretation. It is suggested that a full factorial design be used in studies of drug effects on learning and memory as a control for dissociative effects. 


\section{REFERENCES}

BARRY, H., III, \& KUBENA, R. K. An operant technique for training discrimination between drug and nondrug state. Amer. Psychologist, 1967, $22,516$.

BOHDANECKY, Z., \& JARVIK, M. E. Impairment of one-trial passive avoidance learning in mice by scopolamine, scopolamine methylbromide, and physostigmine. Int. J. Neuropharmacol, 1967, 6, 217-22.

BURESOVA, O., BURES, J., BOHDANECKY, Z., \& WEISS, T. Effects of atropine on learning, extinction, retention and retrieval in rats. Psychopharmacologia, 1964, 5, 255-263.

CARLTON, P. L. Cholinergic mechanisms in the control of behavior by the brain. Psychol Rev., 1963, 70, 19-39.

DEUTSCH, J. A., \& DEUTSCH, D. Physiological psychology. Homewood, Illinois: Dorsey Press, 1966, 72-88.

DILTS, S. L., \& BERRY, C. A. Effect of cholinergic drugs on passive avoidance in the mouse. J. Pharmacol, exp. Therap., 1967, 158, 279-285.

LEAF, R. C., \& LEAF, S. Recovery time as a measure of degree of conditioned suppression. Psychol. Rep., 1966, 18, 265-266.

OLIVERIO, A. Effects of scopolamine on avoidance conditioning and habituation of mice. Psychopharmacologia, 1968, 12, 214-226.

OVERTON, D. A. State-dependent learning produced by depressant and atropine-like drugs. Psychopharmacologia, 1966, 10, 6-31.

VOGEI, J, R., HUGHES, R. A., \& CARLTON, P. L. Scopolamine, atropine, and conditioned fear. Psychopharmacologia, 1967, 10, 409-416.

\section{NOTES}

1. Supported in part by NIH Grant MH-0722705 to R. A. P. and NSF Grant G1 1309 to the University of Pittsburgh Computer Center.

2. Similar effects have been reported recently by B. D. Berger and L. Stein in a paper read at Eastern Psychol. Assoc. Meeting, April, 1968. 